\title{
Retórica jurídica e poder: uma análise da campanha do Itamaraty por assento permanente no Conselho de Segurança da ONU
}

\author{
Aziz Tuffi Saliba* \\ Hugo Pena**
}

\begin{abstract}
Sumário: Introdução; 1. Contornos e fundamentos da campanha por vaga brasileira no Conselho de Segurança; 2. O precedente único de mitigação da rigidez do núcleo do Conselho de Segurança: o desenrolar da questão da representação chinesa entre 1949 e 1971; 2.1. Primeira alteração (1949): substituição da China continental por Taiwan; 2.2. Segunda alteração (1971): substituição de Taiwan pela China continental. Conclusão. Referências.
\end{abstract}

\begin{abstract}
Resumo: Partindo da constatação de que o Itamaraty mantém acesa a campanha por uma vaga permanente no Conselho de Segurança da ONU, ainda que sem direito a veto, o estudo busca identificar os fundamentos para reforma presentes nos discursos de formuladores e executores da política externa do governo brasileiro. Tendo verificado que a fundamentação dá-se essencialmente em contornos jurídicos, busca-se o lugar e o peso do Direito no único precedente até hoje ocorrido de alterações na composição do núcleo do Conselho de Segurança: a questão da representação chinesa, desenrolada entre 1949 e 1979. A análise dos eventos sugere que as motivações para as mudanças não foram de natureza jurídica. As alterações deram-se não somente em virtude da conjuntura do cenário internacional (estrutura de poder) como também pelo peso alcançado pela China continental no limiar da década de 1970 e sua capacidade de afetar essa estrutura. Identifica-se, assim, a política de poder como determinante da alteração na composição nuclear do Conselho nesse caso específico, sugerindo a vulnerabilidade do embasamento de tal campanha em argumentos jurídicos.
\end{abstract}

\begin{abstract}
The starting point for the present article is Itamaraty's ongoing campaign for a permanent seat in the United Nations Security Council. The aim is to identify the rationale contained in pronouncements of policymakers and officials of Brazilian government. After identifying legal arguments as the cornerstone of the campaign, the authors discuss the relevance of Law in the only precedent so far regarding the change in the permanent composition of the Security Council: the Chinese representation affair, which took place between 1949 and 1979. The analysis of such events indicates that the motivations for changes were not of legal nature; they were rather due not only in virtue of power framework of the international scenario at the time, but also to the weight reached by (continental) China in the late sixties and early seventies. Thus, the authors identify power politics as pivotal in the changes in the core of the UNSC in that particular case and point out that the vulnerability of crafting such campaign on legal grounds.
\end{abstract}

\footnotetext{
* Doutor em Direito Internacional pela UFMG. Mestre em Direito Internacional pela University of Arizona, Estados Unidos. Professor de Direito Internacional Público na Universidade de Itaúna, MG. Visiting fellow no Lauterpatch Center for Internacional Law, Universidade de Cambridge (20082009).

** Mestrando em Direito, área de Relações Internacionais, na Universidade Federal de Santa Catarina (UFSC). Bolsista de mestrado do Conselho Nacional de Desenvolvimento Científico e Tecnológico (CNPq).
} 
Palavras-chave: ONU; Conselho de Segurança; Itamaraty, reforma; membros permanentes; veto.
Keywords: United Nations; Security Council; Itamaraty; reform; permanent members; veto.

\section{Introdução}

O Itamaraty persegue vaga para o Brasil no Conselho de Segurança da Organização das Nações Unidas (ONU). Pleiteia-se não uma vaga permanente, com direito a veto, mas a criação de curiosa categoria híbrida - os permanentes sem direito de veto - jamais prevista pela Carta da ONU, e que inclua o Brasil. Outros pretendentes manifestos são o Japão, a Alemanha e a Índia. O engajamento do governo brasileiro na campanha revela traços de obstinação, sobretudo quando se tem em vista as negativas expressas por dois membros permanentes do Conselho de Segurança: Estados Unidos e China. Mesmo diante desse nível de resistência, o intento persiste.

Na seção 2 busca-se identificar, nos discursos de pessoas envolvidas na formulação e execução da política externa do governo brasileiro, os fundamentos declarados para a campanha pela vaga no Conselho. Os argumentos invocados para fundamentá-la partem da constatação de alterações na conjuntura mundial, tendo em conta o contraste entre 1945 e os dias de hoje, para afirmar, em seguida, a necessidade de mudança, fundamentada em termos de representatividade e legitimidade do Conselho, e de igualdade soberana entre os Estados. Da constatação fática - a mudança conjuntural - vem a fundamentação em termos de dever ser. A lógica da campanha pela reforma é normativa. O discurso é jurídico.

Na seção 3 parte-se para a análise do único precedente de alterações no núcleo (supostamente permanente) da estrutura do Conselho de Segurança - uma vez que a proposta de reforma incide sobre esse ponto -, que foi a questão da representação chinesa, desenrolada entre 1949 e 1971 . Busca-se, nesse precedente, o lugar do dever ser: quer-se saber qual foi o papel dos argumentos jurídicos na determinação dessa questão.

Por fim, as informações levantadas são cruzadas na conclusão. Ressalva-se que o estudo não tem a pretensão de generalizar a partir de um só caso, extraindo regras gerais que definam a natureza da política internacional. No entanto, se o assunto é a reforma no núcleo do Conselho de Segurança, torna-se útil analisar as instâncias em que alterações em sua composição tenham ocorrido, identificando quais fatores desempenharam papel significativo e quais não foram relevantes. Generalizar não é possível, mas comparar é. 
Ressalva-se, ainda, que a utilização de precedentes ocorridos no contexto de Guerra Fria e diretamente permeados pela racionalidade do jogo de antagonismo bipolar pode ou não ser traiçoeira quando se pretende deles extrair elementos para comparação com fato atual. A racionalidade bipolar mudou, reconhece-se o lugar de cenários de interdependência complexa que admitem mudanças de regime não fundamentadas exclusivamente na estrutura de poder (KEOHANE; NYE, 1988). No entanto, a política do poder ainda tem seu lugar na conformação das relações internacionais contemporâneas ${ }^{1}$.

\section{Contornos e fundamentos da campanha por vaga brasileira no Conselho de Segurança}

A pretensão de governos brasileiros de ingressar em diretórios de grandes potências não é novidade: pode ser retraçada à Sociedade das Nações e seu Conselho Permanente, após a Primeira Guerra Mundial², e esteve também presente após a Segunda Guerra Mundial, em cogitações sobre o desenho do Conselho de Segurança da $\mathrm{ONU}^{3}$. Após anos em latência, foi reacesa na década de 1990

\footnotetext{
${ }^{1}$ Robert Keohane e Joseph Nye propõem quatro modelos de interpretação de mudanças de regime nas relações internacionais, que vão além do conceito de poder como capacidade de determinar comportamentos ou de controlar resultados. O primeiro beira o determinismo econômico: as inovações tecnológicas e as alterações no modo de produção ocasionam mudanças na estrutura das relações internacionais. O segundo é a província do realismo: as mudanças são resultado de alterações na estrutura de poder (unipolaridade, bipolaridade, multipolaridade, ascensão e queda de potências). Os atores relevantes são os Estados e a agenda internacional é hierarquizada (distinção entre high e low politics), com a segurança militar ocupando o grau mais alto de importância. O terceiro modelo é o da estrutura de questões. Aqui já se adentra a província da teoria da interdependência complexa. As relações internacionais são moldadas não de uma maneira geral, segundo o poder político-militar, mas pelas assimetrias de poder em cada tópico de uma agenda internacional não-hierarquizada (cada assunto tem sua própria estrutura de poder: o petróleo, o predomínio marítimo, as relações monetárias, culturais etc.). Por fim, e adentrando mais ainda a interdependência complexa, a estrutura de organização internacional coloca as mudanças no campo institucional, com regras do jogo. A perspectiva dos autores é relativista, no sentido de que cada situação concreta deve ser explicada segundo modelo apropriado (KEOHANE; NYE, 1988). No presente estudo procura-se demonstrar que alterações ocorridas na estrutura permanente do Conselho de Segurança são passíveis de explicação pelo segundo desses modelos: o da estrutura de poder.

2 "Foi o governo Artur Bernardes que fez da campanha do assento permanente o seu objetivo diplomático fundamental, conscientemente perseguido desde 1923, para o qual se voltaram os maiores esforços da chancelaria" (GARCIA, 1994, p. 7).

${ }^{3}$ Relata Hilderbrand que o presidente norte-americano Franklin Roosevelt, durante a Conferência de Dumbarton Oaks, tentou assegurar uma vaga de membro permanente para o Brasil, com base no seu "tamanho, recursos e ativa participação na [segunda] guerra". A proposta encontrou uma série de óbices. Primeiro, o Conselho, que inicialmente teria 11 assentos, passaria a ter 12. Para evitar-se um
} 
(SEITENFUS, 1994). Nas proximidades de 2005, aos 60 anos da organização, a mobilização para reformá-la em vários aspectos, inclusive o Conselho, intensificouse. O fracasso da reforma não implicou o abandono da campanha, que continua acesa e presente nos atos e pronunciamentos de governo.

Em 23 de setembro de 2008, em discurso na Assembléia Geral da ONU, um dos pontos levantados pelo presidente Luiz Inácio Lula da Silva foi precisamente a necessidade de reformar o Conselho de Segurança (O ESTADO DE SÃO PAULO, 2008b). Outros acontecimentos recentes contribuem para revelar a consistência (no sentido de perenidade) e atualidade da campanha, se ela já não fosse política abertamente declarada (BRASIL, MRE, 2008). Texto de editorial da Folha de São Paulo de 29 de março de 2008 noticiou que observadores brasileiros participariam em eleições do Zimbábue, como resultado do aceite do Itamaraty ao convite de Robert Mugabe. O editorial estabeleceu vinculação entre o aceite e "a obsessão do Itamaraty por uma vaga permanente no Conselho de Segurança da ONU" (FOLHA DE S. PAULO, 2008b, A2). Além disso, a corrente campanha militar no Haiti é invocada como demonstração da contribuição do governo brasileiro para a manutenção da paz e segurança internacionais, na tentativa de provar o merecimento de vaga permanente ou algo que se pareça com isso.

A campanha tem sido mantida mesmo diante da recorrência de negativas por aqueles que detêm poder de decisão sobre eventual reforma. Condoleeza Rice, em visita ao Brasil em março de 2008, declarou que o governo dos Estados Unidos não apoiava o pleito do Itamaraty porque endossava as aspirações japonesas ao Conselho.

Lula tocou no tema em reunião com Rice na quinta-feira, em Brasília. Para ele, o Brasil poderia ser o representante de tal mecanismo [o conselho de defesa sulamericano] junto ao Conselho de Segurança da ONU. Se a criação da nova entidade contou com a simpatia da chefe da diplomacia americana, a representação na ONU não teve a mesma receptividade. (FOLHA DE S. PAULO, 2008a, A14)

número par de membros, restariam então duas alternativas: (1) reduzir o número de membros nãopermanentes, o que tornaria o número de membros eleitos menor que o de não-eleitos; (2) aumentar o número de assentos para 13, "um número de azar, que Roosevelt nunca aceitaria". A inclusão do Brasil poderia acarretar, também, a exigência de inclusão de outros Estados, de outras áreas, por parte dos soviéticos. Ademais, Hilderbrand aponta que não apenas o Brasil não era uma grande potência, mas que pairavam incertezas quanto a "sua unidade, forma de governo e capacidade bélica". Por fim, tendo em vista que a maior parte dos países da América Latina é de língua e colonização espanhola, poderia haver um clamor, na região, por um país representativo de tal grupo. Diante de tais óbices e das objeções da União Soviética e do Reino Unido, a delegação americana demoveu o presidente Roosevelt da idéia (HILDERBRAND, 1990, p. 123-125). 
Esta não foi a primeira negativa. Antes da reforma de 2005, o governo chinês acenava com a possibilidade de apoiar as pretensões do Itamaraty em troca de concessões comerciais (OLIVEIRA, 2004), mas essa posição mudou e a proposta do G4 - formado por Japão, Alemanha, Brasil e Índia - de ampliação do Conselho foi negada (O ESTADO DE S. PAULO, 2005).

Isso não quer dizer que haja resistência por parte de todos os membros permanentes do Conselho de Segurança. Nicolas Sarkozy (ESTADO DE S. PAULO, 2008a) e Gordon Brown (ESTADO DE S. PAULO, 2007) declararam publicamente o apoio dos governos francês e inglês, respectivamente. Ainda assim permanece o fato de que a aprovação da reforma tem como um de seus requisitos a ausência de negativa por parte de qualquer dos membros permanentes. A persistência da política externa do governo brasileiro em seu objetivo de inclusão nos grandes diretórios internacionais é admirável diante da igual persistência de seus fracassos. Talvez seja possível falar em patologia ou obsessão com a questão, face aos renovados esforços e ao conseqüente dispêndio de recursos nela investidos. Mas quais são os argumentos oficialmente levantados para sustentar a pretensão?

Em seu discurso de abertura da $63^{\mathrm{a}}$ sessão da Assembléia Geral da ONU, o presidente Lula levantou a questão da necessidade de reforma do Conselho de Segurança:

As Nações Unidas discutem há quinze anos a reforma do Conselho de Segurança. A estrutura vigente, congelada há seis décadas, responde cada vez menos aos desafios do mundo contemporâneo. Sua representação distorcida é um obstáculo ao mundo multilateral que todos nós almejamos. Considero, nesse sentido, muito auspiciosa a decisão da Assembléia Geral de iniciar prontamente negociações relativas à reforma do Conselho de Segurança. (O ESTADO DE S. PAULO, 2008b)

Muitos dos pontos levantados são constantes nos pronunciamentos referentes a esse ponto da política externa no governo brasileiro por seus integrantes: a mudança do cenário de 1945 para os dias atuais é sempre enfatizada como expressiva de déficit ou distorção de representatividade de países que teriam ascendido em importância ao longo do tempo (o Brasil, propõe-se, seria um deles). Pronunciamentos de Celso Amorim, ministro das Relações Exteriores, e de Ronaldo Motta Sandenberg, então membro da representação diplomática permanente do Brasil na ONU e integrante da delegação brasileira no Conselho de Segurança (em 2005), contribuem para a identificação de certos pontos persistentes na fundamentação da campanha pela reforma. 
Em entrevista concedida a $O$ Estado de São Paulo em 16 de março de 2008 e reproduzida na página eletrônica do Ministério das Relações Exteriores, Celso Amorim afirmou:

O Brasil e a torcida do Flamengo acham que a ONU deve ser reformada. Ela não pode ter hoje a mesma estrutura de 1945- - sobretudo seu órgão mais poderoso, que é o Conselho de Segurança. Isso não tem cabimento. A obstinação de reformar a ONU, se quiser falar assim, continua. Não é que o Brasil quer uma cadeira como se fosse ganhar a Copa do Mundo. Agora, quais são os países que podem contribuir para um Conselho de Segurança mais equilibrado? Quem são aqueles que melhor refletem as mudanças do mundo? Qualquer governo no Brasil que se afastar dessa questão, rapidamente voltará a ela. [...] Agora estamos numa fase de negociações. Posso dizer uma coisa clara: não haverá membros permanentes da mesma forma como foram os da carta de 1945. Membro permanente com poder de veto, isso não será mais possível. A longo prazo, não teremos países-membros com poderes tão arbitrários como os de hoje. Não é mais possível deter essa evolução. (BRASIL, MRE, 2008)

Apesar do tom descontraído da entrevista, a resposta de Amorim revela elementos importantes. A imanência é um deles. Há afirmação de que qualquer governo voltaria à questão da cadeira brasileira no Conselho se ela fosse abandonada. A continuidade da campanha é justificada como uma naturalidade da política externa brasileira. A resposta evoca, ainda, o contexto alterado: não há mais, hoje, a mesma estrutura mundial de 1945. Chama atenção a alusão ao poder arbitrário de alguns membros. Fala-se de evolução em tom de necessidade.

Em artigo publicado antes da tentativa de reforma de 2005 por Ronaldo Motta Sandenberg, então membro da representação diplomática permanente do Brasil na ONU e integrante da delegação brasileira no Conselho de Segurança, há pontos em comum com a posição exposta acima:

[...] não mais vivemos o remoto mundo de 1945. Nem a ONU simplesmente espelha as realidades daquele ano. São flagrantes as mudanças e não parece necessário recapitulá-las. Por certo, desde o começo da década passada, o ritmo dessas mudanças se acelerou e tudo leva a crer que continuará a fazê-lo nos próximos anos. Nesse contexto, 2005 constituirá um marco essencial no caminho de grandes transformações na diplomacia multilateral e, portanto, requererá atenção ainda maior para as definições políticas em curso de adoção nas Nações Unidas e no mundo e, em conseqüência, para as perspectivas de que o Brasil venha a ocupar uma posição internacional. (SANDENBERG, 2005, p. 347) 
Após evocar conceitos como representatividade dos Estados-membros da ONU, igualdade soberana e democratização das relações internacionais, afirma:

Com relação a esta última questão [a expansão da composição do Conselho], por orientação presidencial e sob a condução segura do chanceler Celso Amorim, o Brasil está alçando seu perfil e, especificamente, recebeu significativas manifestações de apoio à sua aspiração. Para que o Conselho mantenha a autoridade que lhe garante relevância e eficácia, é, a nosso ver, imprescindível alterar sua estrutura para torná-lo mais legítimo e mais representativo da realidade contemporânea, com a participação das nações em desenvolvimento - da América Latina, África e Ásia - como membros permanentes e também eleitos. (SANDENBERG, 2005, p. 364)

A autoridade do Conselho é vinculada, no texto, à sua legitimidade. Para que seja mais legítimo é necessário torná-lo mais representativo da realidade, o que implicaria a participação de países em desenvolvimento não só como membros rotativos, mas também como membros permanentes.

Os fundamentos para a reforma e a inclusão do Brasil como membro permanente sem direito a veto são apresentados, de maneira resumida, em termos de (1) uma realidade atual que não é a mesma da composição original do Conselho, em 1945, implicando (2) déficit de representatividade dos países em desenvolvimento, que acaba por afetar (3) a legitimidade do órgão.O meio para torná-lo mais (4) democrático e (5) atento ao princípio da igualdade soberana é, portanto, reformá-lo.

O raciocínio é normativo: orientado em termos de dever ser. O Conselho deve ser representativo, legítimo, democrático e deve respeitar a igualdade de soberania entre os Estados. Parece natural que as pretensões políticas de um Estado venham acompanhadas da retórica jurídica legitimadora. O problema reside em acreditar que a retórica jurídica possa surtir efeitos quando o assunto é reforma no núcleo do Conselho de Segurança. Houve dois precedentes de reforma no Conselho. Um deles foi a modificação de 1965, que ampliou o número de membros não-permanentes. O outro - único a incidir sobre o núcleo do Conselho - foi a questão da representação chinesa, desenrolada entre 1949 e 1971. Como o governo brasileiro pretende ocasionar modificações nesse núcleo, este último precedente é particularmente relevante para o levantamento de fatores que motivam alterações na composição permanente do Conselho. 


\section{O precedente único de mitigação da rigidez do núcleo do Conselho de Segurança: o desenrolar da questão da representação chinesa entre 1949 e 1971}

Em 26 de junho de 1945, data da assinatura da Carta da $\mathrm{ONU}^{4}$, a "República da China" (termo empregado pelo Artigo 23 da Carta, de 1945 aos dias de hoje) foi definida como um dos cinco membros permanentes do Conselho ${ }^{5}$, em virtude de sua magnitude territorial e populacional (CONFORTI, 2005, p. 54). Nessa época, a China era uma só: não existia a divisão entre China continental e Taiwan. Chiang Kai Shek era o governante do território chinês considerado em seu todo.

Com a revolução comunista, em outubro de 1949, o território correspondente a China continental e sua população passaram a estar sob o governo de Mao Tse Tung. Lá foi estabelecida a República Popular da China. Chiang Kai Shek, governante deposto, migrou seu governo para Taiwan, passando a governar população relativamente pequena e território insular ${ }^{6}$.

\subsection{Primeira alteração (1949): substituição da China continental por Taiwan}

Em 18 de novembro de 1949, a ONU recebeu notificação do governo da República Popular da China. Seu conteúdo era a requisição do assento chinês nos órgãos da $\mathrm{ONU}$, incluindo todos os direitos e obrigações correspondentes ao status de membro permanente no Conselho (BRIGGS, 1952, p. 192). O intento de Mao Tse Tung "imediatamente recebeu o suporte dos Estados socialistas, bem como de um grupo de Estados do terceiro mundo, mas encontrou oposição muito forte por parte da maioria dos Estados-membros, liderada pelos Estados Unidos"7 (CONFORTI, 2005, p. 51).

Apesar da explicação original para a formação do núcleo permanente do Conselho, que teria levado em conta os aspectos territorial e populacional da China, a decisão foi a de conferir a representação da "República da China" na ONU ao governo de Chiang Kai Shek. A questão da representação chinesa não foi submeti-

\footnotetext{
${ }^{4}$ A versão aqui da Carta da ONU aqui utilizada é a que consta de SALIBA, 2008.

${ }^{5}$ Apelidados de Permanent 5 ou $P-5$.

${ }^{6}$ Tradução livre. Segundo CONFORTI (2005), a população era de 10 milhões e a área de 14 mil km², referentes à República da China. Duas Chinas passaram, portanto, a existir. Configurava-se, a partir desse momento, o problema da representação chinesa não só no Conselho de Segurança, mas em todos os órgãos da ONU.

${ }^{7}$ Tradução livre.
} 
da ao Conselho e, portanto, não pôde sofrer veto por parte da União Soviética (uma vez que não se saberia qual das delegações chinesas deveria sentar-se ao Conselho para definir a questão). Tampouco foi objeto de decisão da Assembléia Geral. Ao invés disso, a decisão veio de um Comitê de Credenciais previsto pelas regras de procedimento tanto da Assembléia Geral quanto do Conselho, que rejeitou a delegação da China continental, a República Popular da China, em 1949 (CONFORTI, 2005). Taiwan, ou República da China, passou a contar com direito de veto e com o status de membro permanente do Conselho de Segurança a partir de então (CONFORTI, 2005, p. 51-2).

É importante observar, no entanto, que nada mudou em termos formais. A "República da China" era quem continuava a reter a representação na ONU. Podese encontrar, nesse ponto, uma justificativa jurídica de ordem formal para a decisão: o artigo 23 da Carta da ONU foi cumprido ao pé-da-letra, desde que se aceite, é claro, que Taiwan era a continuação do Estado antecessor. Entretanto, esse aspecto formal escondia a radical alteração fática subjacente: a de que a República da China, pela drástica redução territorial e populacional sofrida em 1949, já não era ator de peso na determinação na paz e segurança internacionais. Por essa razão a mudança na representação chinesa desconfigurou o Conselho enquanto órgão que refletia a realidade de poder no mundo (GOODRICH, 1958, p. 286). É difícil sustentar a continuidade do Estado "República da China" após a perda de esmagador percentual de território e população: mas foi o que aconteceu, segundo a decisão sobre as credenciais chinesas.

Com a manobra no Comitê de Credenciais, evitou-se, apesar dos protestos soviéticos $^{8}$ (ZORGBIBE, 1994a, p. 122), que mais um Estado comunista detivesse poder de veto no Conselho de Segurança: uma alteração no esquema de Ialta que o

\footnotetext{
${ }^{8}$ Em razão da decisão de expelir a China continental e de reconhecer Taiwan como continuação da "República da China", a União Soviética protestou não só verbalmente, mas retirando-se do Conselho de Segurança em 13 de janeiro de 1950, após tentativa de aprovar resolução que propunha a exclusão da delegação de Taiwan do mesmo Conselho (BRIGGS, 1952, p. 199). Essa retirada objetivava travar o Conselho, com fundamentação no Artigo 27 da Carta da ONU, que estabelecia, como hoje ainda estabelece, a necessidade dos votos afirmativos de todos os membros permanentes para que uma resolução em assuntos não procedimentais fosse aprovada. Essa forma de protesto não surtiu, no entanto, o efeito que os representantes soviéticos esperavam. Quando a Coréia do Norte atacou a Coréia do Sul, pouco tempo depois, o Conselho de Segurança foi reunido para deliberar sobre o assunto e aprovou a decisão de uso da força na península coreana. Inaugurou-se a interpretação (reformadora) da Carta da ONU, segundo a qual a ausência de um membro permanente não implica veto, apesar de a linguagem expressamente exigir votos afirmativos. Pesou, na criação dessa interpretação desviante, a obrigação, também estabelecida pela Carta, de que todos os membros do Conselho se façam representar permanentemente nas sessões (CONFORTI, 2005). Os soviéticos voltaram a integrar o Conselho em $1^{\circ}$ de agosto de 1950 (BRIGGS, 1952, p. 200).
} 
governo dos Estados Unidos, como pivô do bloco capitalista, não estava disposto a aceitar.

Durante a década de 1950, as relações sino-soviéticas foram de cooperação, com a China sob a proteção do escudo nuclear soviético (LEVINE, 1975-6, p. 637). Esse alinhamento, que implicava posição de subserviência de Pequim à liderança de Moscou e permitia a configuração de uma ordem mundial bipolar, viria a ser abalado na década seguinte e daria ensejo a nova correlação de forças, com a emergência de uma China nuclear e desalinhada do bloco soviético.

\subsection{Segunda alteração (1971): substituição de Taiwan pela China continental}

Durante a década de 1960, União Soviética e China continental começaram a desentender-se por dois fatores principais (ZORBIBE, 1994b). Ambos têm repercussão na esfera política.

O primeiro deles era de natureza ideológica. A União Soviética tinha projeto centralizante para o socialismo em âmbito internacional ou até mesmo mundial, e esse centro era Moscou. Já o governo da China continental desejava autodeterminarse, rejeitando a idéia do socialismo ou comunismo internacionalista uno. Tinha seu próprio projeto e taxava de imperialistas as pretensões soviéticas. A existência dessa variante era, em si, um ponto de atrito com Moscou.

$\mathrm{O}$ segundo fator dizia respeito à autonomia do programa nuclear chinês (ZORGBIBE, 1994b, p. 11). Mao Tse Tung desejava que a China entrasse para o quadro das potências nucleares, mas sem controle soviético. Esse desalinhamento de políticas nucleares resultou na suspensão da ajuda soviética ao programa nuclear chinês.

O corte na ajuda tecnológico-militar soviética não impediu que o governo chinês prosseguisse seu programa independentemente. A primeira bomba atômica chinesa foi testada em outubro de 1964; a primeira bomba de hidrogênio, em junho de 1967 (ZORGBIBE, 1994, p. 14). A gravidade da situação é relatada por Zorgbibe, segundo o qual a ascensão da China ao grupo das potências termonucleares teria incitado os soviéticos a planejar ataque nuclear preventivo ao arsenal nuclear chinês; em 1969, o confronto parecia iminente (1994, p. 14). Choques armados na fronteira sino-soviética (embora sem uso de armas nucleares) chegaram a acontecer nesse mesmo ano (DITTMER, 1981, p. 496-7; LEVINE, 1975-6, p. 637). Configurava-se a cisão entre Pequim e Moscou. A relação entre os dois países transformou-se em uma "inimizade crescentemente amarga" (DITTMER, 1981, p. 493).

\footnotetext{
${ }^{9}$ Tradução livre.
} 
O bloco comunista já não parecia, afinal, um bloco. O bipolarismo da Guerra Fria dava lugar a nova conformação de forças ${ }^{10}$ com os desentendimentos acentuados entre a China continental e a União Soviética (ZORGBIBE, 1994b, p. 70; DITTMER, 1981, p. 498; LEVINE, 1975-6, p. 639). É nesse contexto que entra na pauta da agenda externa norte-americana a diplomacia triangular ${ }^{11}$ e a reaproximação com Pequim, explorando suas diferenças com Moscou (DITTMER, 1981, p. 485; ROSS, 1986, p. 257-8). Segundo Zorgbibe (1994b), o jogo triangular favorecia os Estados Unidos, cujo confronto com a União Soviética jamais fora direto, enquanto esta e a China dividiam a maior fronteira do mundo em uma relação contenciosa (ou mesmo belicosa). Ainda segundo ele, os Estados Unidos jogavam "mais livremente" porque não possuíam "adversários sistemáticos" e estavam "menos prisioneiros de preconceitos doutrinários"12 (1994b, p. 70). Dittmer (1981) escreve no mesmo sentido. Para ele, os Estados Unidos eram o pivô do triângulo que surgia. Isso se dava em razão de suas relações tanto com a União Soviética quanto com a China serem "positivas"13, enquanto as destes últimos países eram de crescente inimizade e mesmo violentas ${ }^{14}$ (1981, p. 493, 496, 498).

${ }^{10}$ Segundo Ross (1986), apesar de a China, ao final da década de 1960, não ter arsenal nuclear comparável aos dos Estados Unidos e União Soviética, sua população, tamanho e base de recursos naturais tornava-a significativa para os interesses das duas superpotências; configurava-se a multipolaridade na estrutura de poder. Explica, ainda, que embora alguns países europeus tivessem atributos semelhantes, a flexibilidade e a imprevisibilidade das relações Estados Unidos-União Soviética-China é que criavam a "dinâmica multipolar do triângulo estratégico" (1986, p. 258 [tradução livre]). A multipolaridade relevante, portanto,

não se referia à Europa ou ao Japão, mas à mise-en-scène da China como ator de peso para os interesses das superpotências em um cenário internacional conflituoso.

${ }^{11}$ A doutrina da diplomacia triangular foi instaurada durante o governo de Richard Nixon, em que Henry Kissinger era Secretário de Estado, e representou uma "mudança extraordinária" na política externa dos Estados Unidos (BERMAN, 1980, p. 561). Essa mudanç

a deve-se não somente à reaproximação com Pequim, desde o rompimento em 1949, mas também à superação da teoria do dominó, oficialmente enunciada durante o governo de Dwight Eisenhower, em 1954, e segundo a qual "o Ocidente deve forçosamente ajudar cada país ameaçado pelo comunismo, porquanto a queda de um tornaria mais fácil o triunfo marxista em outra zona” (PINCUS, 1970, p. 9). Com o afastamento da teoria do dominó e o conseqüente início da retirada norte-americana do Vietnã, programa de campanha de Nixon, os Estados Unidos já não constituíam ameaça à segurança chinesa (DITTMER, 1981, p. 498). Isso permitiu a reaproximação com a China, conduzida por Kissinger e Nixon que, ao inaugurar a diplomacia triangular, pautavam as relações exteriores norte-americanas em "uma análise dos interesses nacionais essencialmente em termos de poder, em vez de ideológica" (DITTMER, 1981, p. 498 [tradução livre]).

12 Tradução livre.

${ }^{13}$ Ao afirmar que as relações entre Estados Unidos e União Soviética seriam positivas, Dittmer considera que a détente amenizava as relações entre os dois países (1981, p. 493).

${ }^{14}$ Para Levine (1975-6), no entanto, a China percebia tanto a União Soviética quanto os Estados Unidos como superpotências inimigas (1975-6, p. 656). As inimizades não eram, porém, de igual intensidade, já que, segundo Levine, Pequim encarava Moscou como uma ameaça externa primária à sua segurança e à integridade do processo revolucionário chinês (1975-6, p. 653), destoante do soviético. 
Assim, a diplomacia triangular baseada nas diferenças entre Pequim e Moscou, em seu cisma, favorecia os Estados Unidos que, ao explorar tais diferenças, incrementava seu poder relativamente à União Soviética. Era interessante ter uma China que pudesse causar maior incômodo aos soviéticos. O fomento das diferenças enfraquecia a oposição comunista ao bloco capitalista.

Não demorou muito para que a nova alteração no núcleo "duro" do Conselho de Segurança fosse providenciada. Em 1971, após visita secreta de Kissinger a Pequim (MAGNOLI, 1996, p. 65), o assento permanente de Taiwan é-lhe retirado e conferido ao governo de Mao, por decisão da Assembléia Geral (UNITED NATIONS GENERALASSEMBLY, 1971). "Como a URSS e a China podiam agora trocar acusações em um fórum global, a disputa foi ainda mais internacionalizada" ${ }^{15}$ (DITTMER, 1981, p. 497).

Destaque-se que a China continental estava sob o governo de Mao nos dois momentos relevantes: 1949 e 1971. Os Estados Unidos capitanearam sua retirada do Conselho no primeiro momento, bem como sua volta em 1971. Aliás, não só o governo da China continental permaneceu o mesmo, como também o de Taiwan. Não houve alterações territoriais ou populacionais relevantes que justificassem juridicamente a alteração de 1971. Taiwan continuava a ser uma ilha e a China continental continuava a possuir população e território esmagadoramente maiores.

Tampouco teria mudado a continuidade formal da "República da China" (o argumento atrelado ao nome), que pesou em 1949 na justificação da manobra de exclusão da China comunista, já que Taiwan ainda carregava (em 1949 como em 1971) o nome do Estado precedente, e assim continuava (formalmente, para todos os efeitos) o antecessor. Nada disso importou diante dos novos fatos na geopolítica - o cisma sino-soviético e o ganho de poder (sobretudo nuclear) da China - e suas implicações para os interesses do governo norte-americano. Embora o aspecto jurídico-formal pudesse ter pesado para a decisão no primeiro momento (1949), ele não pode ser invocado para justificar o ocorrido em 1971 sem que seja acompanhado de larga medida de esquizofrenia: se Taiwan era a continuidade da "República da Chi-

\footnotetext{
${ }^{15}$ Tradução livre. As conclusões de Chai (1979), em artigo em que analisa estatisticamente as políticas chinesas de votação na Assembléia Geral em relação às superpotências da época e ao terceiro mundo entre 1971 e 1977, dão significativo suporte à afirmação de Dittmer de que a reinserção da China na ONU proporcionava vitrine de exposição de seus desentendimentos. Chai afirma que dos "quatro membros permanentes do Conselho de Segurança, a concordância das votações soviéticas com a China foi a maior em assuntos relativos a colônias, menor que a da França em assuntos de política e segurança no período considerado como um todo, e desde 1974 a menor em questões de controle de armas e desarmamento. Há algumas indicações de que a disputa entre os dois gigantes comunistas nessa questão crucial tem sido intensificada" (CHAI, 1979, p. 403 [tradução livre]).
} 
na" em 1949, e se não houve alterações de governo ou mudanças substanciais de território e população (note-se aqui a presença de três elementos constitutivos do Estado), não haveria razão para se esperar dois resultados jurídicos distintos para duas realidades semelhantes nos aspectos que são relevantes para essa análise jurídica. Em outros termos, a análise jurídica não contém os elementos necessários para explicar essas alterações.

O veto mudou de mãos: a estrutura central do Conselho de Segurança foi mais uma vez alterada. A China continental foi readmitida, com todos os seus direitos restaurados; Taiwan, retirado, permanece fora da ONU até hoje. Diante dessa alteração no núcleo do Conselho de Segurança, cabe analisar as repercussões desse precedente para a campanha do governo brasileiro por vaga no Conselho.

\section{Conclusão}

Os dados apresentados na seção anterior permitem a afirmação de que, embora fatores jurídicos pudessem estar presentes na explicação do deslocamento do veto da China para Taiwan em 1949 (em razão da continuidade de Estados - governo no exílio - e a questão formal do nome "República da China"), eles não podem explicar o retorno do poder de veto à China continental em 1971 se os elementos relevantes para a análise jurídica (de maneira geral: governo, território e população) mantiveram-se, em larga medida, constantes. Sugere-se, ainda mais, que os eventos de 1949 foram revestidos de roupagem jurídica para legitimar razões políticas subjacentes: evitar-se o ingresso de mais um membro alinhado ao bloco comunista no Conselho de Segurança da ONU naquele cenário específico.

O precedente está, em seus dois momentos, permeado pela racionalidade da Guerra Fria. Nesse sentido, a conjuntura foi fator importante. Parte da explicação para as alterações precisa passar pela relação antagônica entre Estados Unidos e União Soviética. Entre os dois momentos relevantes, 1949 e 1971, a China não só adquiriu armamentos nucleares como rompeu relações com a União Soviética. Passou a pesar, com isso, para o equilíbrio de poder no mundo. Sua readmissão na ONU foi instrumental para os fins da política externa norte-americana, orientada, nos dois momentos, por sua preocupação com a União Soviética.

O argumento da alteração na conjuntura mundial entre 1945 e os dias atuais está presente na campanha do Itamaraty. Mas a conjuntura mundial já foi alterada diversas vezes, das mais variadas formas, sem que isso ocasionasse mudança na estrutura central do Conselho de Segurança. Quando o número de membros da sociedade internacional cresceu em decorrência do processo de descolonização, o 
número de membros rotativos do Conselho foi alterado. Mas não seu núcleo. Alemanha e Japão reconstruídos e revelados potências econômicas mundiais já na década de 1960 não implicaram alterações. Os países exportadores de petróleo tiveram importância majorada após os choques do petróleo na década de 1970, mas o Conselho não mudou. A Guerra Fria acabou - mudança conjuntural marcante ao final do século XX - e não ocasionou mudanças no Conselho.

Essa linha de raciocínio pode ser interpretada como reveladora da necessidade da mudança. Esse parece ser o posicionamento do Itamaraty. O fato de que alterações substanciais na conjuntura mundial não tenham sido refletidas no núcleo do Conselho não significaria que elas não deveriam tê-lo sido. Faz-se, assim, o retorno ao argumento normativo, fundado no dever ser, e a invocação de fatores como representatividade, legitimidade, democracia e igualdade soberana. Propõese, aqui, outra interpretação.

A necessidade da mudança no núcleo do Conselho e os argumentos jurídicos para embasá-la não foram levantados em 1949 ou 1971. Em 1949, a questão foi a de "preservar" o veto nas mãos do governo pró-Ocidental de Chiang Kai Shek. Não se pode dizer que a roupagem jurídica usada para tanto tenha sido de mudança: seu sentido era de manutenção, apesar das radicais alterações fáticas subjacentes. Em 1971, o jurídico sequer pesou, como já demonstrado anteriormente. A China revelou seu peso e influência no jogo de antagonismo entre Estados Unidos e União Soviética, e foi reposicionada onde melhor pudesse contribuir para a permanência do cisma sino-soviético.

Se a alteração conjuntural foi importante para explicar o assunto da representação chinesa na ONU, ela não foi, contudo, suficiente. Aspectos jurídicos mostraram-se inócuos como fatores de mudança, embora tenham tido seu lugar na roupagem para a preservação do status quo em um primeiro momento. Se o jurídico não serve para completar a explicação conjuntural, restam fatores de ordem pragmática. O peso adquirido pela China foi um deles. Seus alinhamentos (ou realinhamentos) políticos, outro. E não se pode desprezar o fator relativo a quem detinha o controle sobre as manobras nos dois momentos: as alterações na composição do Conselho atenderam, em cada momento da questão da representação chinesa, aos objetivos da política externa norte-americana. Nota-se, assim, o lugar da política de poder como chave de interpretação do ocorrido.

É evidente que a generalização a partir de caso único não é viável. Não se pretende afirmar que toda reforma na composição permanente do Conselho de Segurança obedecerá ao mesmo padrão apresentado no assunto da representação chinesa. O que se pode afirmar é que, em mais de 60 anos de existência da ONU, 
as únicas mitigações da rigidez da estrutura central do Conselho deram-se por considerações pertinentes à política do poder, e não foram juridicamente provocadas. ${ }^{16}$

Se esse cenário fosse representativo de um contexto maior, seria possível afirmar que a estratégia fixada na retórica jurídica, no dever ser, é inócua. O discurso é importante como instrumento de legitimação daquilo que se faz, mas não substitui a causa fundamental das mudanças: as relações de poder. Se a dinâmica do cenário internacional de fato se der nesses moldes - e parece ser este o caso quando analisadas as alterações na estrutura central do Conselho de Segurança -, é conveniente que o Itamaraty repense a obsessão pela reforma do Conselho, em termos de viabilidade. Para ingressar nos diretórios das grandes potências, parece antes ser necessário tornar-se uma delas. Isso implica incidir diretamente sobre $o$ balanço de poder no mundo, sobre sua estrutura, coisa que não parece poder-se atingir por meio do discurso jurídico.

\section{Referências}

BERMAN, William C. Global Games (Review: KISSINGER, Henry. White House years. Boston: Little, Brown, 1979). Reviews in American History. Vol. 8, n. 4 (Dec., 1980), pp. 561-566.

BRASIL, MINISTÉRIO DAS RELAÇÕES EXTERIORES (MRE). Discursos, artigos, entrevistas e outras comunicações. Entrevista concedida pelo ministro das Relações Exteriores, embaixador Celso Amorim, ao jornal "O Estado de São Paulo". 16 mar. 2008. Disponível em: <http://www.mre.gov.br/portugues/ politica_externa/discursos/discurso_detalhe3.asp?ID_DISCURSO=3267>. Acesso em: 4 abr. 2008.

BOURDIEU, Pierre. O Poder Simbólico. 8. ed. Rio de Janeiro: Bertrand Brasil, 2005.

BRIGGS, Herbert W. Chinese Representation in the United Nations.

International Organization. Vol. 6, n. 2, (May, 1952), pp. 192-209.

\footnotetext{
${ }^{16}$ Utilizou-se, aqui, a metodologia sugerida por Pierre Bourdieu. Para Bourdieu, o "raciocínio analógico, que se apoia na intuição racional das homologias [...], é um espantoso instrumento de construção do objeto. É ele que permite mergulharmos completamente na particularidade do caso estudado sem que nela nos afoguemos [...], e realizarmos a intenção de generalização, que é própria da ciência, não pela aplicação de grandes construções formais e vazias, mas por essa maneira particular de pensar o caso particular que consiste em pensá-lo verdadeiramente como tal. Este modo de pensamento realiza-se de maneira perfeitamente lógica pelo recurso ao método comparativo, que permite pensar racionalmente um caso particular constituído em caso particular do possível [...]“ (BOURDIEU, 2005, p. 32-3).
} 
CHAI, Trong R. Chinese policy toward the third world and the superpowers in the UN General Assembly 1971-1977: a Voting Analysis. International Organization. Vol. 33, n. 3 (Summer, 1979), pp. 391-403.

CONFORTI, Benedetto. The law and practice of the United Nations. 3. ed. Leiden/Boston: Martinus Nijhoff Publishers, 2005.

DITTMER, Lowell. The strategic triangle: an elementary game-theoretical analysis. World politics. Vol. 33, n. 4 (Jul., 1981), pp. 485-515.

FOLHA DE S. PAULO. Fausto tropical. 29 mar. 2008b. A2.

. Jobim 'venderá' conselho de defesa nos EUA. 15 mar. 2008a. A14.

GARCIA, Eugênio Vargas. A candidatura do Brasil a um assento permanente no Conselho da Liga das Nações. Revista Brasileira de Política Internacional, n. 37, Vol. 1 (1994), pp. 5-23.

GERTH, Hans e MILLS, Wright C. (org.). Max Weber: Ensaios de Sociologia. 2. ed. Rio de Janeiro: Zahar, 1971.

GOODRICH, Leland M. The UN Security Council. International Organization. Vol. 12, n. 3, (Summer, 1958), pp. 273-287.

HILDERBRAND, Robert C. Dumbarton Oaks: the origins of the United Nations and the search for postwar security. Chapel Hill e Londres: The University of North Carolina Press, 1990.

KEOHANE, Robert O.; NYE, Joseph. Poder e interdependencia: la politica mundial en transición. Trad. Herbert Cardoso Franco. Buenos Aires: Grupo Editorial Latino-Americano, 1988.

LEVINE, Steven I. China and the Superpowers: Policies toward the United States and the Soviet Union. Political Science Quarterly. Vol. 90, n. 4 (Winter, 1975-1976), pp. 637-658.

MAGNOLI, Demétrio. O mundo contemporâneo. Relações internacionais 1945-2000. São Paulo: Moderna, 1996.

O ESTADO DE S. PAULO. Brasil e China estão se desapaixonando. diz Economist. 5 ago. 2005. Disponível em: <http://www.estadao.com.br/arquivo/ economia/2005/ not20050805p8643.htm>. Acesso em: 4 abr. 2008.

O ESTADO DE S. PAULO. Leia a íntegra do discurso de Lula na ONU. 23 set. 2008b. Disponível em: <http://www.estadao.com.br/economia/ not_eco246743,0.htm>. Acesso em: 29 out. 2008.

O ESTADO DE S. PAULO. Lula e Brown debatem Doha e Conselho de Segurança. 11 jul. 2007. Disponível em: $<$ http://www.estadao.com.br/economia/ not_eco17517,0. htm>. Acesso em: 4 abr. 2008. 
O ESTADO DE S. PAULO. Sarkozy defende Brasil no G-8 e no Conselho de Segurança. 12 fev. 2008a. Disponível em: <http:/www.estadao.com.br/ nacional/not_nac123434,0.htm>. Acesso em: 4 abr. 2008.

PINCUS, John. Nações ricas e nações pobres: comércio, ajuda externa e desenvolvimento. Trad. Ruy Jungmann. São Paulo: Forense, 1970.

ROSS, Robert S. International Bargaining and Domestic Politics: U.S.-China Relations since 1972. World Politics, Vol. 38, n. 2, (Jan., 1986), pp. 255-287. SALIBA, Aziz Tuffi. Legislação de Direito Internacional. 4. ed. São Paulo: Rideel, 2008.

SANDENBERG, Ronaldo Mota. Brasil, política multilateral e Nações Unidas. Estudos Avançados. Vol. 19, n. 35 (2005).

SEITENFUS, Ricardo Antônio Silva. Para uma nova política externa brasileira. Porto Alegre: Livraria do Advogado, 1994.

UNITED NATIONS GENERAL ASSEMBLY. Resolution 2758 (XXVI).

Restoration of the lawful rights of the People's Republic of China in the United Nations. 25 out. 1971. Disponível em: <http://www.un.org/documents/ga/res/26/ ares26.htm>. Acesso em: 1 jul. 2008.

ZORGBIBE, Charles. Histoire des relations internationales. Du schisme Moscou-Pékin a l'aprés-guerre froide: 1962 a nos jours. v. 4. Paris: Hachette, $1994 b$.

. Histoire des relations internationales. Du système de Yalta aux missiles de Cuba: 1945-1962. v. 3. Paris: Hachette, 1994a. 